Document downloaded from:

http://hdl.handle.net/10251/82707

This paper must be cited as:

Lujan Martinez, JM.; Climent Puchades, H.; Dolz Ruiz, V.; Moratal Martínez, AA.; Borges Alejo, J.; Soukeur, Z. (2016). Potential of exhaust heat recovery for intake charge heating in a Diesel engine transient operation at cold conditions. Applied Thermal Engineering. 105:501-508. doi:10.1016/j.applthermaleng.2016.03.028.

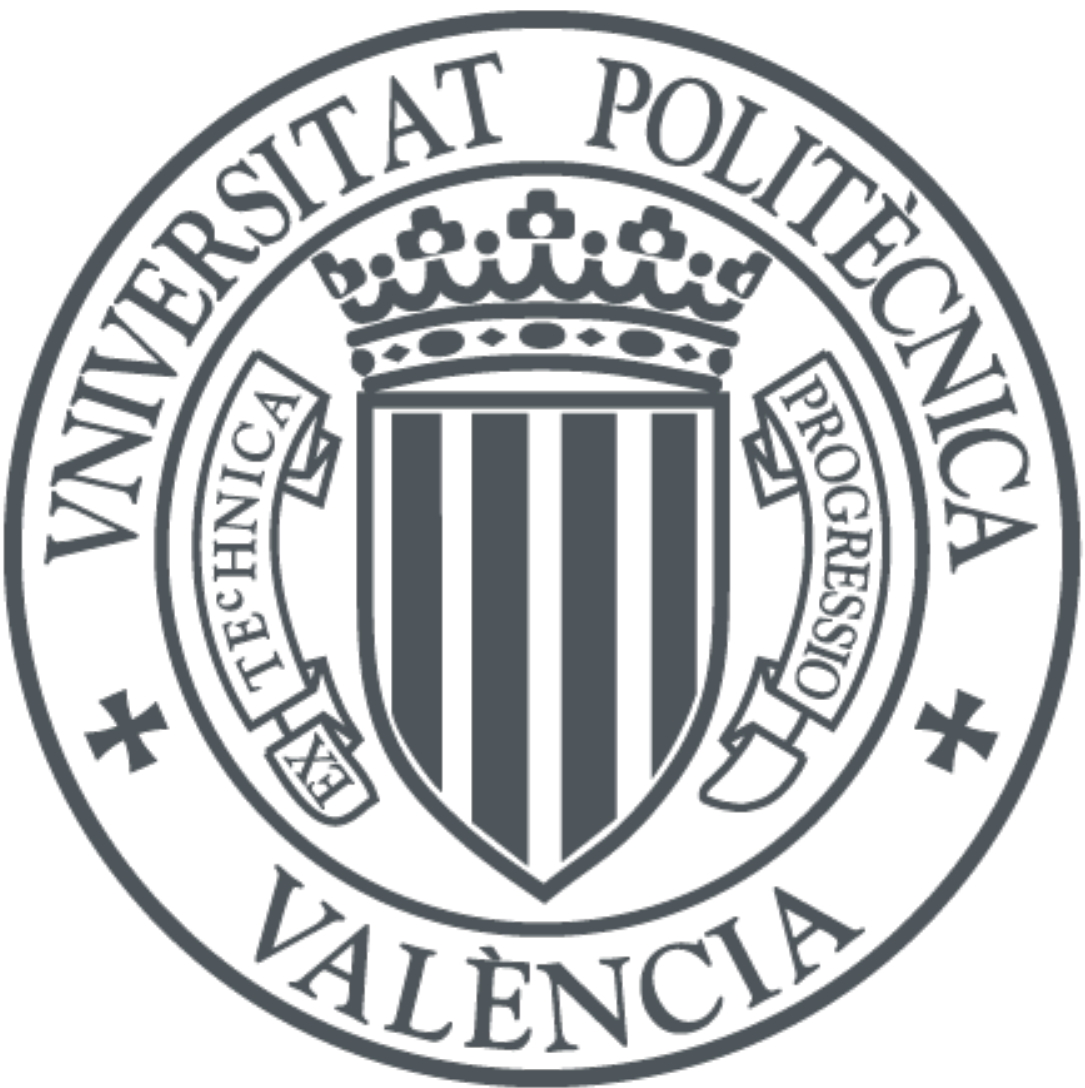

The final publication is available at

http://doi.org/10.1016/j.applthermaleng.2016.03.028

Copyright Elsevier

Additional Information 


\title{
Potential of exhaust heat recovery for intake charge heating in a Diesel engine transient operation at cold conditions
}

\author{
José Manuel Luján ${ }^{a}$, Héctor Climent $^{\mathrm{a}}$, Ausias Moratal $^{\mathrm{a}}$, José Borges-Alejo ${ }^{\mathrm{b}}$, Zoulikha Soukeur ${ }^{\mathrm{b}}$ \\ ${ }^{\mathrm{a}}$ CMT Motores Térmicos, Universitat Politècnica de València, Spain \\ ${ }^{\mathrm{b}}$ Valeo Thermal Systems, R\&D Advanced Development, La Verriere, France
}

\begin{abstract}
In this paper, an experimental facility is implemented with the aim of improving the performance of internal combustion engines working at low ambient temperatures. Pollutant emissions and fuel consumption are one of the major issues that automotive engineers have to face. Cold engine start and warming up analysis have become important topics for researches. In this work, an exhaust heat recovery system for a diesel engine has been proposed as a solution to cold operation negative effects. The energy obtained from the exhaust gases was used to increase the intake air temperature. The experiments were carried out in transient load conditions at three different levels of ambient temperature (up to $-7^{\circ} \mathrm{C}$ ). Exhaust heat recovery was combined with different strategies of exhaust gas recirculation. Intake air heating results with the heat recovery system show a reduction of $65 \%$ in unburned hydrocarbons, $40 \%$ in carbon monoxide and $10 \%$ in fuel use compared to standard air-air intercooler.
\end{abstract}

\section{Introduction}

Increasingly stringent emissions regulations are constantly motivating the automotive industry to develop new systems and strategies. Air-to-fuel ratio control and injection strategies optimization were traditionally enough to avoid excessive emissions. During the last few years, the use of diesel particulate filter (DPF) [1-2] has been a widespread solution to fulfil emission regulations. On the other hand, despite the development in NOx aftertreatment [3] for diesel engines, exhaust gas recirculation (EGR) remains as a cost-effective solution to fulfill current and future NOx emission regulations [4].

As automotive cycles are being more restrictive, it is expected that the operation conditions of the driving tests will consider the effect of running at lower ambient temperature. Under these conditions, fuel consumption and pollutant emissions during the engine warm-up are critical and the techniques commented above may not be able to fulfill properly the emissions requirements. According to the literature [5] and [6], unburned hydrocarbons and carbon monoxide are mainly emitted when engine temperatures remain low. Therefore, a non-negligible effect of the low engine temperature on pollutant emissions during engine warm up is noticed. In this sense, it is proved that under certain conditions, intake air heating can provide benefits such as $\mathrm{CO}$ and $\mathrm{HC}$ emissions reduction, combustion noise control and engine stability improvement after cold starting [7].

Researchers have study the effect on pollutant emissions and engine performance in cold driving cycles [8]. Currently, the U.S Environmental Protection Agency includes a cold cycle of FTP-75 as an optional driving cycle carried out at $-7^{\circ} \mathrm{O}$. It is expected that if future regulations include cold cycles as mandatory, they will be assessed at this temperature.

Several authors have studied the effect of warm-up in engines, methods and systems to reduce the time needed to get the nominal operation conditions. Jarrier et al. [7] explain that during the first minute of warm-up, around $65 \%$ of the combustion energy is used for mass heating, being negligible the heat transfer from the engine to the ambient. Referring to the improvement of cooling systems, researchers have been focused on cooling strategies in order to reduce the engine warm-up time, optimize the heat dissipation in each of the engine operation points and ensure the passenger comfort.

Many authors have researched different ways to get improvements on engine thermal conditions for cold operation. Gumus et al. [9] present a thermal energy storage device (TESD) connected to the engine water jacket, that works on the effect of absorption and rejection of heat during the solid-liquid phase change of heat 
storage material $\left(\mathrm{Na}_{2} \mathrm{SO}_{4}-10 \mathrm{H}_{2} \mathrm{O}\right)$. Pre-heating engine at cold start, at $2{ }^{\circ} \mathrm{C}$, Gumus obtained a $\mathrm{CO}$ and $\mathrm{HC}$ emission decrease about $64 \%$ and $15 \%$ respectively. Broatch et al. [10] evaluated the potential of an intake air heating technology, by means of electrical heaters, for the reduction of pollutant emissions from diesel engine combustion during a NEDC cycle, showing a reduction of $13 \%$ in $\mathrm{HC}, 5 \%$ in $\mathrm{CO}$ and $3 \%$ in NOx but particulate matter increases about $4 \%$. Kauranen [11] proposes a double heat recovery system from the combination of exhaust gas heat recovery system and latent heat accumulator for thermal energy storage, using the energy to heat the engine coolant during a cold start and low engine load.

In this work a different concept is proposed. Exhaust thermal energy is recovered by a heat exchanger placed on the tail of the exhaust line. Recovered heat is driven by a hydraulic installation to the intake manifold where a water/air heat exchanger releases the heat recovered to the intake air instead of heating the engine coolant. However, many authors have analyzed the performance improvement of coolant heating [12-13] instead of intake air. Some advantages have to be highlighted in case of coolant and oil heating:

- Increasing oil temperature reduces friction losses, due to its lower viscosity.

- Energy recovered by coolant is transferred to the engine block, reducing the energy moved from combustion to the cylinder line and cylinder head.

On the other hand, some disadvantages make hard to apply the oil and coolant strategy:

- High thermal inertia of block and coolant engine system as well as thermal losses along with low heat recovery during the first minutes of warming-up produces small temperature increases in engine coolant and oil.

- Initial combustion conditions are not improved. So, cold air is coming inside the cylinder, increasing the combustion time duration and therefore reducing the combustion performance.

The facility performed in this work was used to investigate the capability of an exhaust heat recovery system as well as to study the influence of the intake air temperature on the emissions and performance of a DI Diesel engine working under transient load conditions at low ambient temperatures. The initial air temperature influences on the chemical reaction rate through the rate coefficient, according to the Arrhenius expresion [14], there is an exponential relation between rate constant and temperature. Higher intake air temperatures show a drawback effect on cylinder filling. The higher the temperature is, the lower the density is, and therefore the volumetric efficiency goes down [15]. However at low temperatures the negative effect on the volumetric efficiency is not significant, but the rate of combustion is. Therefore, the intake air temperature increase improves the engine performance. Experimentally it can be proved by the fuel consumption in the cycle

The aim of this research is to analyze how the improvement of combustion boundary conditions, such as air intake temperature, EGR rate and engine coolant temperature, can enhance the engine performance under low temperature conditions. Summing up, the recovery system purpose is the warming-up time reduction, and the engine operation under more optimal conditions, until engine nominal temperatures are reached.

The paper is structured as follows. Section 2 is devoted to the experimental setup and the explanation of the theoretical tools. Section 3 is focused on the balance energy analysis. Section 4 contains the results and analysis of the recovery system effects on the emissions and engine performance during the NEDC cycle starting at $-7^{\circ} \mathrm{C}$ and the impact on the system of different ambient temperatures. Finally, the main conclusions are presented in section 5 .

\section{Experimental setup and methodology}

\subsection{Description of test cell and setup}


In order to analyze the effect of the heat recovery system the experiments with an in line 4 cylinders, 2.0 I, turbocharged HSDI diesel engine were conducted. In Table 1 the features of the engine are shown. The tests were carried out in a climatic chamber where the ambient, coolant and fuel temperatures are under control.

\section{Table 1}

Engine specifications.

\begin{tabular}{ll} 
Cylinder number & In-line 4 \\
Bore $\mathrm{x}$ stroke $\left(\mathrm{mm}^{3}\right)$ & $85 \times 88$ \\
Displacement $\left(\mathrm{cm}^{3}\right)$ & 1997 \\
Compression ratio & $17.6+/-0.5$ \\
Valve number & 16 \\
Valvetrain & Double cam shaft over head \\
Fuel delivery system & Common rail. Direct injection. \\
EGR system & HP and LP cooled EGR \\
Intake boosting & Turbocharger with VGT \\
Intake cooling system & Water charge air cooler (WCAC) \\
Maximum power $(\mathrm{kW} / \mathrm{rpm})$ & $120 / 3750$ \\
Maximum torque $(\mathrm{Nm} / \mathrm{rpm})$ & $340 / 2000$ \\
Torque at maximum power $(\mathrm{Nm})$ & 300 \\
Maximum speed $(\mathrm{rpm})$ & 5200 \\
Specific power $(\mathrm{HP} /$ liter $)$ & 81.5 \\
\hline
\end{tabular}

Engine Intake manifold is a cutting edge design where the classic intercooler is replaced by a water/air heat exchanger, known as Water Charge Air Cooler (WCAC), that is joined to a short intake manifold. High pressure exhaust gas recirculation (HP EGR) duct connects at one side of this short manifold and mixes the exhaust gases with the fresh air trying to avoid HP EGR dispersion between the cylinders [16]. The result is a compact Air Intake Module (AIM) in which lengths are reduced and therefore time response too. Figure 1 shows a drawing of the Intake Air Module. An additional bypass branch allows the intake air flow not to go through the WCAC heat exchanger, in order not to heat or cool it.

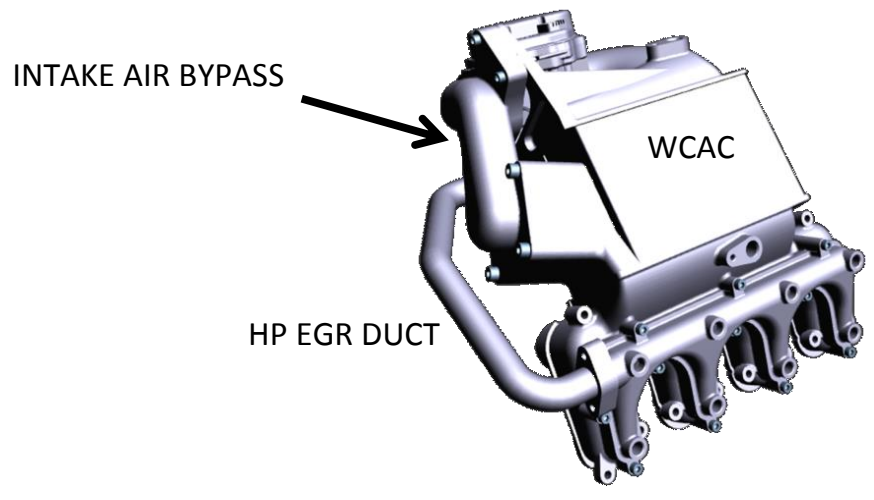

Figure 1. Air Intake Module.

The waste heat recovery system is based on a heat exchanger placed in the exhaust line, between the Diesel particle filter and the low pressure exhaust gas recirculation (LP EGR) extraction. Figure 2 shows a schematic layout of the engine including the heat recovery system. According to this layout the heat exchanger in the exhaust line is used for, simultaneously, both LP EGR cooling and heat recovery. For this reason this unit will be referred as Twin Function Exchanger (TFE). The TFE is connected to the WCAC by means of a coolant circuit. The coolant flow is heated in the TFE using the exhaust gases enthalpy and releases heat to the intake air in the WCAC. The air at the WCAC outlet is mixed with the exhaust gases coming from the HP EGR system and the mixture enters into the intake pipes. It is important to highlight that the WCAC has two functions depending on the 
intake air temperature, on one hand at low temperature it releases the heat recovered by the TFE. On the other hand when intake temperature is high, the WCAC is connected to a cooler in order to work as the classic intercooler does.

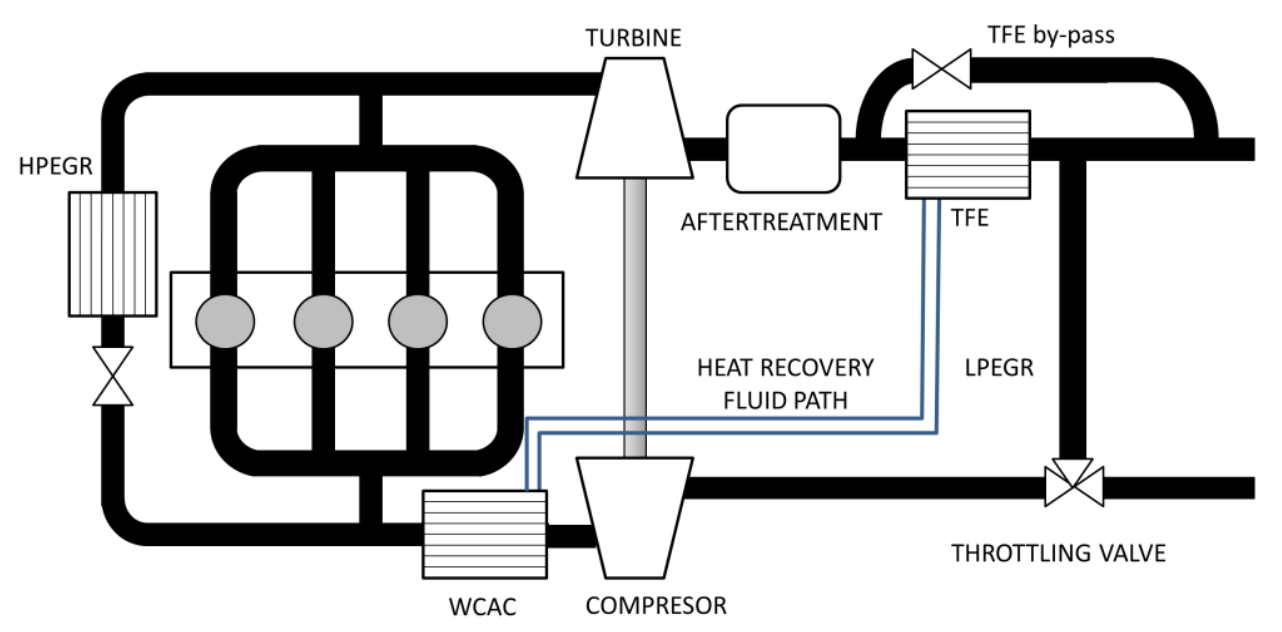

Figure 2. Engine layout.

The sizing of certain heat exchangers of the vehicle (main radiator, CAC...) is driven by the required performance at full load extreme conditions. The WCAC has been designed to be able to reduce the intake air temperature in full load until external ambient temperature. The maximum thermal power transferred in the WCAC is $22 \mathrm{~kW}$. The engine running conditions where the air enthalpy delivered by the compressor is the highest, is at $3500 \mathrm{rpm}$ and $325 \mathrm{Nm}$. The external WCAC volume is 2.25 litres $(20 \times 12.5 \times 9 \mathrm{~cm})$.

The LP EGR coolers are somehow different; they are sized in order to assure no negative impact of high temperatures at the inlet of the compressor when the maximum amount of exhaust gas is recirculated. In our specific case this heat exchanger, called TFE because is providing also the heat recovery function, has been oversized in order to reduce the backpressure in the main exhaust line and avoid any influence of this system on the performance of the engine. The maximum exhaust thermal power delivered in the TFE is $36 \mathrm{~kW}$ at engine full load condition, at $3500 \mathrm{rpm}$ and $325 \mathrm{Nm}$. The TFE volume is 0.583 liters $(18.5 \times 7 \times 4.5 \mathrm{~cm})$.

The coolant pipes connecting both elements, WCAC and TFE, have been designed in order to reduce the coolant volume at the minimal value to avoid thermal inertia and reduce thermal losses between them. The total pipe length of the heat recovery system is 1.2 meters and the coolant volume inside it is 0.34 litres.

Several cases were analyzed at different ambient temperatures in order to study the feasibility of the energy recovery system from low temperatures, $-7 \stackrel{\circ}{\circ} \mathrm{C}$, to higher and less critical temperatures, 0 and $10 \stackrel{\circ}{\circ} \mathrm{C}$. All cases were defined for testing at transients loads of a NEDC cycle. There were tested several configurations of the heat recovery system. The main differences between cases lie in the combination of HP EGR and LP EGR duration as well as the configuration of the WCAC. The first case, AIRCAC reference, represents the current automotive technology. Intake air is always cooled simulating an air-air intercooler. The other test reference is WCAC reference: the WCAC is installed upstream of the intake manifold. In this case, in order to reduce the negative effect of air cooling at low ambient temperatures, no coolant flow goes through the WCAC. Both references don't have the heat recovery system installed, the rest of cases have it. The third case is named as HP 180. The intake air flows through the WCAC. HP EGR is enabled for 180 seconds since the engine coolant temperature has reached $5 \stackrel{\circ}{\circ}$ in order to avoid combustion instabilities due to the EGR activation at low temperatures. Finally the fourth case named as HP 180 Bypass is the same as the third case but the WCAC air by-pass is enabled for the first 100 seconds of the cycle. In all the configurations, LP EGR is enabled once HP EGR is switched off.

Horiba Mexa 7100 DEGR was used to measure $\mathrm{O}_{2}, \mathrm{CO}_{2}, \mathrm{CO}$, using a non-dispersive infrared analyzer, and unburned hydrocarbons with a chemiluminiscent detector. The error of the gas analyzer is in the range of $2 \%$. 
Both intake and exhaust $\mathrm{CO}_{2}$ measurements were recorded in order to obtain the EGR rates. The EGR rate is defined as:

$\mathrm{EGR}=\frac{\dot{\mathrm{m}}_{\mathrm{EGR}}}{\dot{\mathrm{m}}_{\mathrm{AIR}}+\dot{\mathrm{m}}_{\mathrm{EGR}}}$

Where $\dot{m}_{E G R}$ and $\dot{m}_{A I R}$ are the mass flow of EGR gas and fresh air, respectively. Air mass flow was measured by a hot wire anemometer with a measurement error of $1 \%$. Equation 1 can be expressed as a function of a specific pollutant concentration, like $\mathrm{CO}_{2}$, measured in the intake and exhaust manifold [17].

$\mathrm{EGR}=\frac{\left[\mathrm{CO}_{2 \mathrm{INT}}\right]-\left[\mathrm{CO}_{2 \mathrm{ATM}}\right]}{\left[\mathrm{CO}_{2 \mathrm{EXH}}\right]-\left[\mathrm{CO}_{2 \mathrm{ATM}}\right]}$

Where $\left[\mathrm{CO}_{2 \text { INT }}\right],\left[\mathrm{CO}_{2 \mathrm{ATM}}\right]$ and $\left[\mathrm{CO}_{2 \mathrm{EXH}}\right]$ are the carbon dioxide concentration in the intake, ambient and exhaust respectively.

Fuel consumption along the NEDC cycle was measured with an AVL fuel balance, with a measurement error of $0.2 \%$. Temperatures at the intake were measured downstream and upstream the WCAC. Besides the main parameters, other variables were recorded, such as engine speed, fuel rate injection, boost pressure, air mass flow and exhaust temperatures with the aim to compare the repeatability of the cycles and obtaining data to get a thermal characterization of both WCAC and TFE. All measurement signals were sampled at $10 \mathrm{~Hz}$.

Once the NEDC cycle has finished, the engine is put under specific conditions of load to regenerate the particulate filter [18]. After that, test cell is cooled for several hours in order to ensure the same initial conditions of all cycles carried out.

\subsection{Repeatability and pollutant emissions calculation}

In addition to the errors of the measurement devices, engine performance and boundary conditions variability affects the result obtained. In order to quantify the variability pattern, the repeatability of the experiments was evaluated by comparing the exhaust emissions measurements and fuel consumption of four NEDC cycles carried out in different days at $-7^{\circ} \mathrm{C}$ [19]. The repeatability study shows maximum variations of the total emissions about $4 \%$ for $\mathrm{CO}, 10 \%$ for $\mathrm{HC}$ and $2 \%$ in case of fuel consumption. For each variable: fuel, $\mathrm{CO}$ and $\mathrm{HC}$, variability is characterized through the relative difference of each case compared to the average. The calculation of the error due to the variability, presented as $\boldsymbol{\alpha}$, is shown in the Equation 3.

$\alpha=\max \left\{\left|\frac{\widehat{x}-\bar{x}}{\bar{x}}\right|,\left|\frac{\bar{x}-\bar{x}}{\bar{x}}\right|\right\}$

Where $\mathrm{X}$ represents the accumulated value of the variable under study, fuel, $\mathrm{HC}$ or $\mathrm{CO}$, at each time. $\widehat{\mathrm{X}}, \overline{\mathrm{X}}, \overline{\mathrm{X}}$ are the maximum, minimum and average amount respectively of the variable at each point of the NEDC cycle .

Figure 3 shows the average of the accumulated values of fuel consumption and pollutant emissions along the NEDC cycle. The chart includes an error bar at the main points of the cycle. 

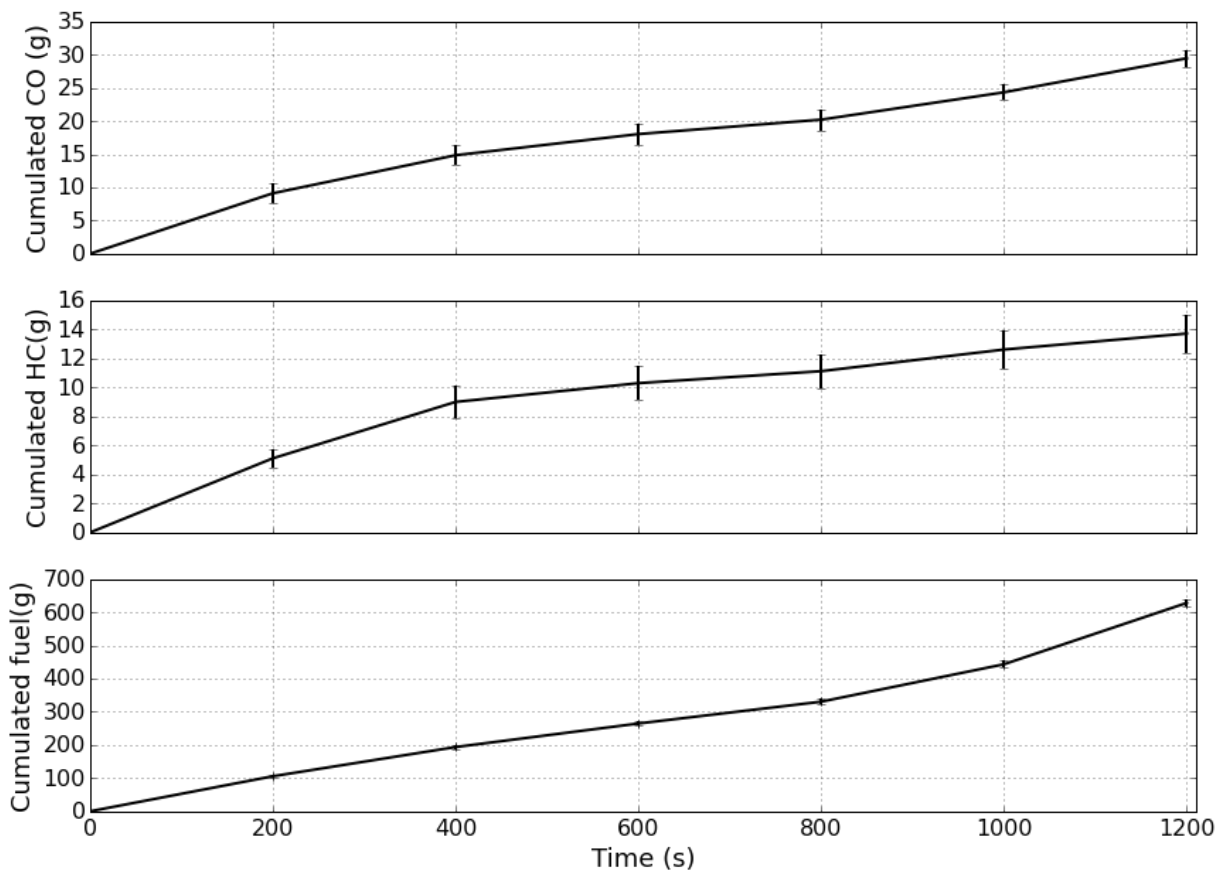

Figure 3. Accumulated pollutant emissions and fuel consumption at $-7^{\circ} \mathrm{C}$ in a NEDC cycle.

Once chemical pollutants have been recorded by the gas analyzer, it is necessary to process the data in order to ensure the right time span and avoid the mismatch between pollutant emissions and the other engine variables, such as air and fuel mass flow. The existence of a delay in pollutant analysis is due to two different sources. On one hand, there is an internal delay necessary to analyze the sample that depends on the type of pollutant [20]. On the other hand the distance between the sample point and the gas analyzer forces the existence of a delay defined by the gas velocity and the length of the sample pipes. The gas speed through the sample pipes is produced by the vacuum pressure generated by the gas analyzer pump, which remains equal during the whole cycle. Some authors have implemented behavior models [20] while other authors analyze the delay by correlation methods comparing the pollutant measurement with other related variables like engine speed [21-22]. In this study a correlation method is used, previous to the assessments it was studied the second source delay by carrying out NEDC cycles in order to compare the pollutant pick emissions against the power pick demands. In addition the first EGR rate grows up is compared to the EGR valve opening.

The pollutant sample point is located upstream the Diesel oxidation catalyst to analyze the effect on pollutant emissions of the heat recovery system acting alone. Flow rate mass emissions are calculated using the pollutant concentrations and the air and fuel mass flow, according to the Equation 4, in order to know how much pollutants are released to the atmosphere.

$\dot{\mathrm{m}}_{\text {pollutant }}=\frac{\mathrm{M}_{\text {pollutant }}}{\mathrm{M}_{\text {air }}} \cdot\left[\mathrm{C}_{\text {pollutant }}\right] \cdot\left(\dot{\mathrm{m}}_{\mathrm{air}}+\dot{\mathrm{m}}_{\text {fuel }}\right)$

Where $\mathrm{M}_{\text {pollutant }}$ and $\mathrm{M}_{\text {air }}$ are the molecular weight of pollutants and air respectively. [ $\left.\mathrm{C}_{\text {pollutant }}\right]$ is the measured pollutant concentration and $\dot{\mathrm{m}}_{\text {air }}$ and $\dot{\mathrm{m}}_{\text {fuel }}$ are the mass flow of fresh air and fuel respectively.

\subsection{Energy balance analysis}

Energy fluxes distributions in the engine are studied during the whole cycle [23]. First thermodynamics law is applied in the engine to analyze how the energy distribution occurs along the cycle. The procedure is similar to the one presented in [24]. Energy terms are estimated from delivered data by thermocouples, flow meters and fuel balance. The energy analysis is simplified in four main terms. The heat release $\left(\dot{Q}_{\text {release }}\right)$ by the engine, that besides of the energy delivered by the combustion it involves the inlet energy of fuel and air, the engine power $\left(\mathrm{N}_{\mathrm{e}}\right)$ recorded by the electrical brake, the enthalpy per time unit of exhaust gases $\left(\mathrm{H}_{\mathrm{exh}}\right)$ and finally, the 
miscellaneous losses $\left(\dot{Q}_{\text {misc }}\right)$. This last term includes several ways of losses: heat transmission losses to the coolant system, lubrication fluid, surroundings, and thermal inertia of the overall engine. In addition to the heat losses, miscellaneous term involves the friction losses. Power terms are obtained from Equations 5, 6 and 7 .

$\dot{\mathrm{Q}}_{\text {release }}-\mathrm{N}_{\mathrm{e}}-\mathrm{H}_{\text {exh }}=\dot{\mathrm{Q}}_{\text {misc }}$

Where $\dot{Q}_{\text {release }}$ is the total in-cylinder heat release, $\mathrm{N}_{\mathrm{e}}$ is the engine power and $\mathrm{H}_{\mathrm{exh}}$ is the enthalpy of exhaust gases.

$\mathrm{H}_{\mathrm{exh}}=\dot{\mathrm{m}}_{\mathrm{g}} \cdot \mathrm{c}_{\mathrm{g}} \cdot \mathrm{T}_{\mathrm{exh}}$

Where $\dot{m}_{g}$ is the exhaust gas flow, $c_{g}$ is the specific heat of exhaust gases and $T_{\text {exh }}$ is the exhaust gases temperature.

$\dot{\mathrm{Q}}_{\text {release }}=\dot{\mathrm{Q}}_{\text {comb }}+\mathrm{H}_{\text {air-in }}+\mathrm{H}_{\text {fuel-in }}-\mathrm{H}_{\mathrm{vf}}$

Where $\dot{Q}_{\text {comb }}$ is the combustion energy rate, $\mathrm{H}_{\text {air-in }}$ is the intake air enthalpy, $\mathrm{H}_{\text {fuel-in }}$ is the injected fuel enthalpy and $\mathrm{H}_{\mathrm{vf}}$ is the vaporization fuel enthalpy.

\subsection{Effectiveness of WCAC and TFE}

Heat exchanger effectiveness shows the temperature increase of a fluid respect the theoretical value that it could reach [25]. Effectiveness $(\varepsilon)$ calculation of TFE are shown in Equations 8 and 9. Equation 8 shows the TFE effectiveness when it works as a heat recovery system.

$\varepsilon_{\text {TFE_Heat_recovery }}=\frac{\mathrm{T}_{\mathrm{TFE} \_ \text {out_coolant }}-\mathrm{T}_{\mathrm{TFE} \_ \text {in_coolant }}}{\mathrm{T}_{\text {in_gas }}-\mathrm{T}_{\mathrm{TFE}} \text { in_coolant }}$

Where $\mathrm{T}_{\text {TFE_out_coolant }}, \mathrm{T}_{\mathrm{TFE} \_ \text {in_coolant }}, \mathrm{T}_{\mathrm{in} \text { _gas }}$ is the outlet coolant TFE temperature, inlet coolant TFE temperature and inlet gas temperature respectively. Equation 9 shows the cooling performance of the TFE when LP EGR is enabled.

$\varepsilon_{\text {TFE_cooler }}=\frac{T_{\text {in_gas }}-T_{\text {out_gas }}}{T_{\text {in_gas }}-T_{\text {TFE_in_coolant }}}$

Where, $\mathrm{T}_{\text {in_gas }}, \mathrm{T}_{\text {out_gas }}, \mathrm{T}_{\mathrm{TFE} \_ \text {in_coolant }}$ is the inlet gas temperature, outlet gas temperature and inlet coolant TFE temperature respectively. Equation 10 shows the WCAC effectiveness when the heat recovery system is running.

$\varepsilon_{\text {WCAC }}=\frac{T_{\text {out air }}-T_{\text {in air }}}{T_{\text {WCAC }_{\text {in coolant }}}-\mathrm{T}_{\text {in air }}}$

Where $\mathrm{T}_{\text {out air }}, \mathrm{T}_{\mathrm{in} \text { air }}, \mathrm{T}_{\mathrm{WCAC}_{\mathrm{in} \mathrm{coolant}}}$ is the outlet air temperature, inlet air temperature and inlet coolant WCAC temperature respectively. Large heat losses and thermal inertia of fins and housing decrease the heat exchanger effectiveness. It is important to remark that the thermal inertia works as an energy storage which at thermal transient conditions can demand or release heat. In addition, the heat capacities of fluids affect to the temperatures reached.

\section{Energy analysis results}

\subsection{Engine block energy balance}

The evolution of the main energy terms of Equation 5 is depicted in Figure 4 for an NEDC cycle carried out at -7 ${ }^{\circ} \mathrm{C}$ of ambient temperature. In order to perform the analysis, several time intervals inside the cycle are considered: 0-200, 200-400, 400-600, 600-800, 800-1000 and 1000-1200 seconds. The energy terms are given as a fraction of the total in-cylinder energy in each interval. Heating-up analysis is difficult to carry out due to the 
transient load conditions. For this reason, the energy analysis is obtained as the average value of each energy term at the mentioned time intervals. These time steps represent the main points of the NEDC cycle.

For the first 400 seconds the energy analysis shows similar values. $50 \%$ of the total energy concerns to miscellaneous losses, around $40 \%$ of energy is available on exhaust gases and the rest of energy, around $10 \%$, is effective power. Between 400 and 600 seconds the energy distribution changes. Exhaust enthalpy shows higher energy fraction with a $47 \%$ than miscellaneous losses with a $42 \%$. Effective power remains around $10 \%$. Between 600 and 800 seconds the increase of exhaust enthalpy is noticeable. Exhaust enthalpy rises to $52 \%$ and miscellaneous losses are reduced to $37 \%$. The reason of the miscellaneous losses reduction over time is the combustion improvement and increase of thermal efficiency as the NEDC proceeds. Energy released to the engine block and coolant circuit is reduced as these components increase their temperature. Regarding effective power, it remains at $10 \%$.

Finally, during the last two time steps the higher engine load increases the effective power to $20 \%$ approximately. Between 800 and 1000 seconds exhaust enthalpy fraction is reduced to $44 \%$ while miscellaneous losses percentage remains equal. At the last time step exhaust enthalpy fraction increases to $47 \%$ while miscellaneous losses fraction is reduced to $30 \%$.

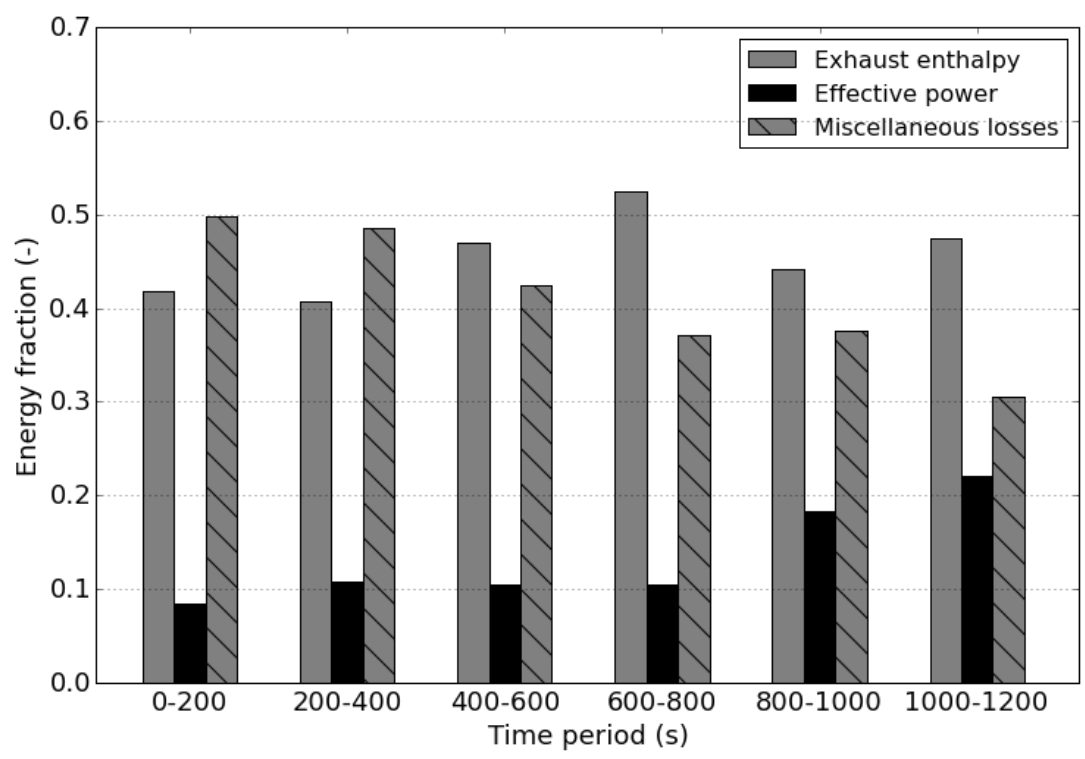

Figure 4. Energy fraction evolution during the NEDC cycle at $-7^{\circ} \mathrm{C}$.

\subsection{TFE and WCAC performance}

Cycle-averaged TFE and WCAC effectiveness are calculated with Equations 8, 9 and 10. Equations 8 and 10 are applied for the first 400 seconds of the cycle, when the heat recovery system delivers the energy from the exhaust to the intake air. Equation 9 is applied while LP EGR is enabled, since the first 180 seconds until the end of the cycle, in order to characterize the EGR cooling performance of the TFE.

The effectiveness of the TFE and WCAC when the heat recovery system is working is $11 \%$ and $89 \%$ respectively. Both heat exchangers are performed to work in counter flow configuration. TFE shows low effectiveness as a consequence of the large value of the coolant heat capacity compared to the exhaust gases. Coolant temperature increase is small and differences between the inlet gas and the outlet coolant temperatures are significant. On the other hand, WCAC effectiveness is high due to the reverse effect. The air heat capacity is low, so air temperature reaches the coolant inlet one. Regarding the LP EGR cooling performance of TFE the effectiveness is $94 \%$. In this case the high effectiveness shows the important cooling effect of the TFE on the exhaust gases. Figures 5 and 6 depict the gas and coolant temperatures of both heat exchangers: TFE and WCAC respectively. The 
temperature evolution is shown for the first 400 seconds, when heat recovery system is working in the heating mode.

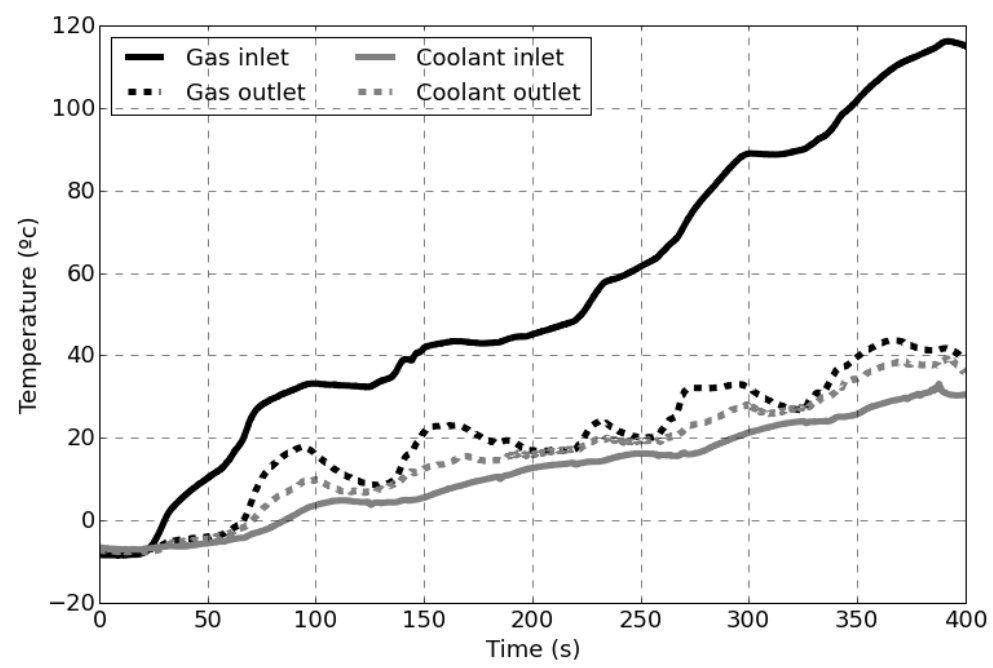

Figure 5. TFE gas and coolant temperatures

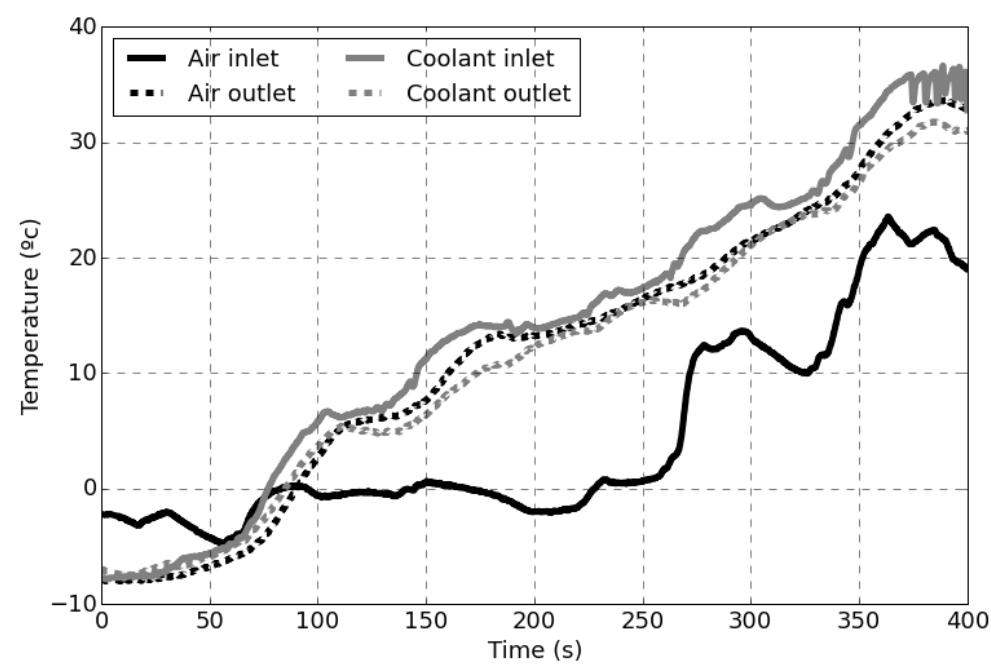

Figure 6. WCAC air and coolant temperatures.

\section{Engine performance results and discussion}

The heating recovery system is applied under different ambient temperature to analyse its influence on the intake air heating benefits. In case of engine tests at $0^{\circ} \mathrm{C}$ and $10^{\circ} \mathrm{C}$ the reference tests are those with WCAC working without cooling flow during the first 800 seconds. Exhaust raw emissions were measured at the beginning of the exhaust line, between the turbine outlet and the diesel oxidation catalyst.

\subsection{Assessment of engine performance at $-7^{\circ} \mathrm{C}$}

The heat recovery system is designed to work under low ambient temperature conditions. Figure 7 shows the intake air temperature evolution during the NEDC cycle with the different configurations presented in previous sections. All the configurations provide very similar results in the first 200 seconds since the HP EGR strategy is enabled. Afterwards, once the EGR strategy is switched from HP to LP configuration, the effect of the heat recovery system is noticiable. 
For the first 100 seconds, when EGR is not enabled yet, lower intake temperatures are recorded for AIRCAC case due to the cooling effect of WCAC, which is simulating an AIRCAC with a coolant temperature equal to the ambient temperature. On the other hand, the WCAC bypass case shows a bit higher intake temperature, which demonstrates the negative effect of the WCAC cold walls in the beginning.

While HP EGR is enabled (between the first 100 and 180 seconds), temperatures of different cases are close between them and show very similar profiles. The reason of this fact is the high enthalpy of exhaust, not cooled, gas recirculation. Hydrocarbons and $\mathrm{CO}$ are produced at condition of defect of oxygen and low temperature as a result of the partial oxidation of the fuel, phenomena known as incomplete combustion. Under less critical ambient temperatures the EGR reduces both the peak combustion temperature and oxygen presence, producing an increase of $\mathrm{CO}$ and hydrocarbons, in order to reduce NOx emissions. However at low temperatures the use of EGR becomes useful avoiding partial oxidation because of the higher impact of initial temperature than the oxygen dilution. This is the reason of performing no cooled HP EGR in the first stages of the cycle.

From 180 seconds, HP EGR is replaced by LP EGR and the temperatures of the different cases show important reductions because of it.

Between 500 and 800 seconds the temperature differences between cases are due to the heat recovery system. Intake air temperature differences between the cases are around $40{ }^{\circ} \mathrm{C}$ higher than the AIRCAC reference test $\left(15^{\circ} \mathrm{C}\right.$ in case of WCAC 0 -flow).

At 800 seconds of the NEDC cycle the extra-urban cycle is performed, so higher engine loads are applied. In order to avoid intake overheating the heat recovery system is connected to the engine coolant instead of the WCAC. Therefore, after this point the WCAC actuates as a cooler and the TFE as a standard LP EGR cooler. In the 0 -flow case, the thermal control actuates opening the coolant valve showing a noticible intake temperature reduction according to Figure 7 . Since 800 seconds all cases show an increasingly intake temperature due to the higher engine load. In the case of AIRCAC reference, temperature remains constant with small changes until high load increases the intake temperature.

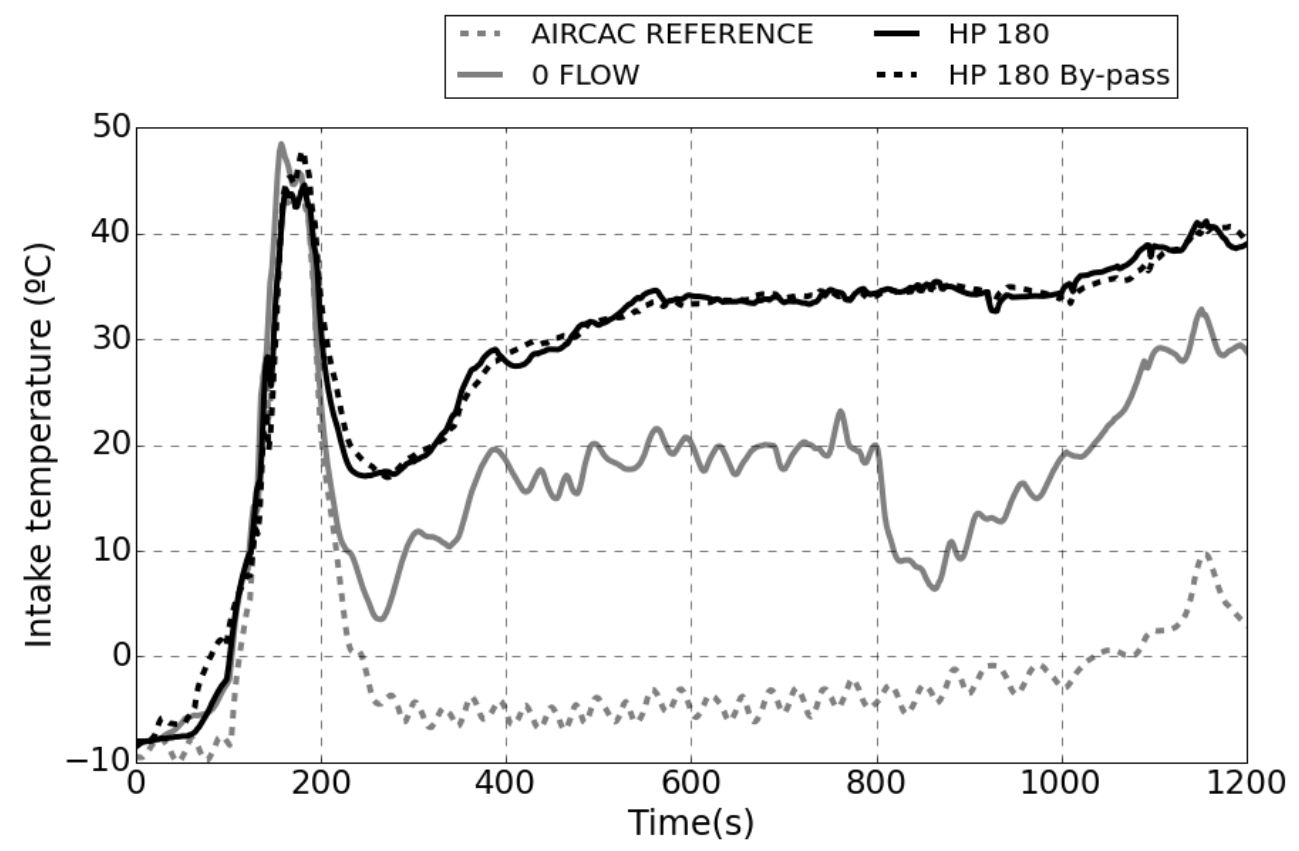

Figure 7. Intake temperature profile during the NEDC cycle.

Figure 8 shows the relative reduction in fuel consumption and pollutant emissions compared to the AIRCAC reference. The charts represent the accumulative reduction for the main points of the NEDC cycle. 
According to the charts, it can be observed two stages on hydrocarbons emissions and fuel consumption evolution. In the first stage, between 200 and 400 seconds, there is an important reduction. From this point, the reduction becomes lower noticeable until the end of the NEDC cycle.

For the first 200 seconds HP 180 By-pass shows lower CO emissions due to the effect of bypassing intake air. The initial improvement in HP 180 By-pass is due to the lower heat transmission losses from the intake air to the cold walls of WCAC and therefore intake temperature is slightly higher than the others in the beginning, as explained in Figure 7. On the other hand there is not improvement on fuel consumption and unburned hydrocarbons

After 200 seconds it is observed a clear tendency: higher intake temperatures reduce the $\mathrm{CO}, \mathrm{HC}$ emissions and fuel consumption. All cases show better performance than the reference case. Since 200 seconds the classification of cases depending on the magnitude of reduction remains constant. 0 -flow is the case with lower improvements, followed by HP 180 and finally HP 180 By-pass which shows higher improvements in fuel consumption and mainly in $\mathrm{CO}$ emissions compared to the standard HP 180.

Comparing HP 180 and HP 180-Bypass cases, it is important to highlight the positive effect of the WCAC By-pass on $\mathrm{CO}$ reduction. In the beginning of the NEDC cycle, CO emissions are critical due to the low operation temperature of the engine. From the point of view of fuel consumption, the differences are low and, regarding unburned hydrocarbons, there is no difference for the whole NEDC cycle between these two configurations.
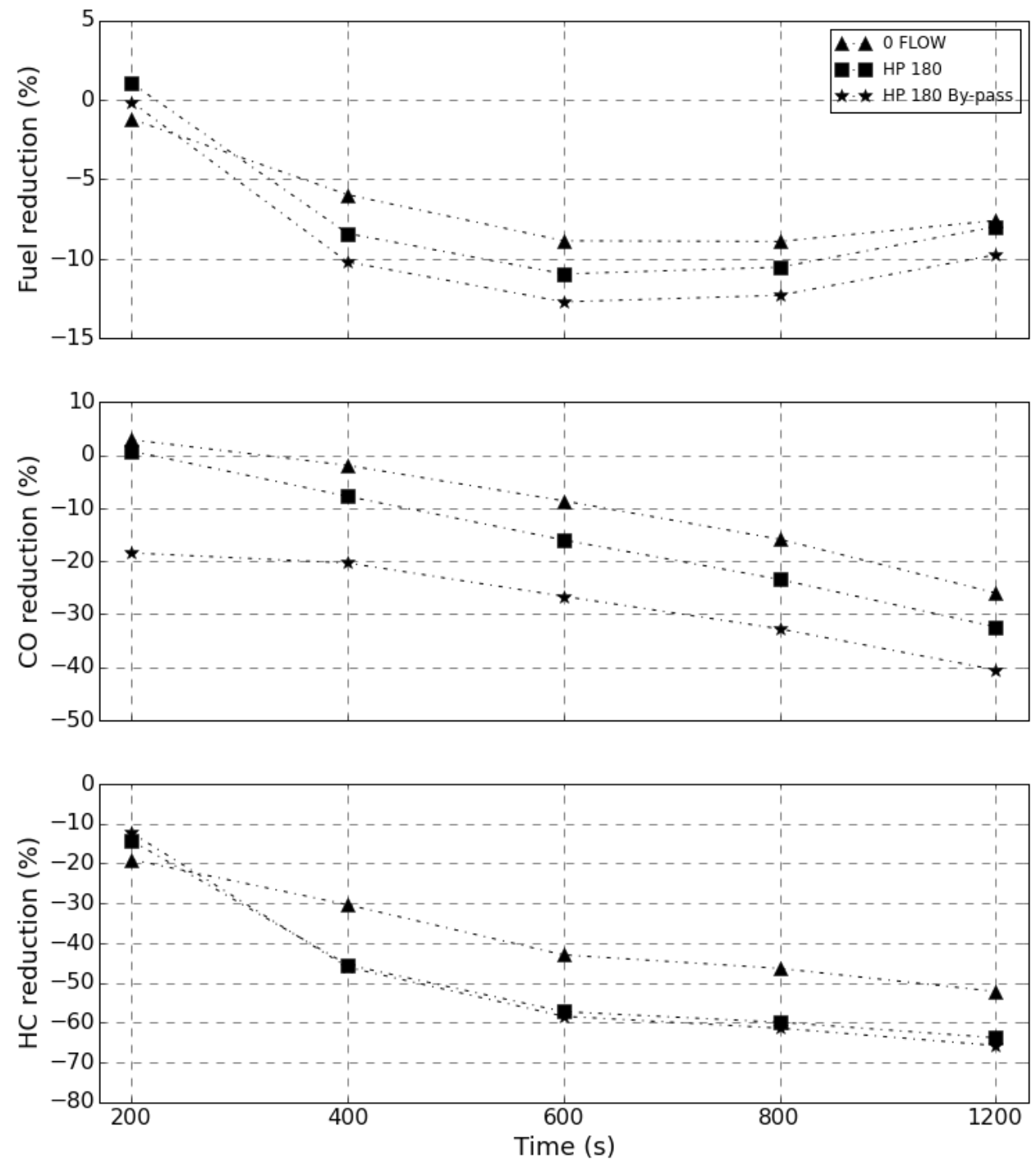

Figure 8. Reduction of fuel and pollutant emissions by time period. 
Total accumulated fuel and pollutant variation of the whole NEDC cycle is depicted in Figure 9 compared to the AIRCAC reference. Higher intake temperature increases the combustion efficiency and therefore fuel consumption is reduced. While fuel reduction keeps similar in all cases, between $7 \%$ and $10 \%$ compared to the AIRCAC, $\mathrm{CO}$ and $\mathrm{HC}$ emissions show important reductions comparing the different cases. Using WCAC by-pass is observed a reduction of $8 \%$ in CO in HP 180 By-pass compared to the HP 180.

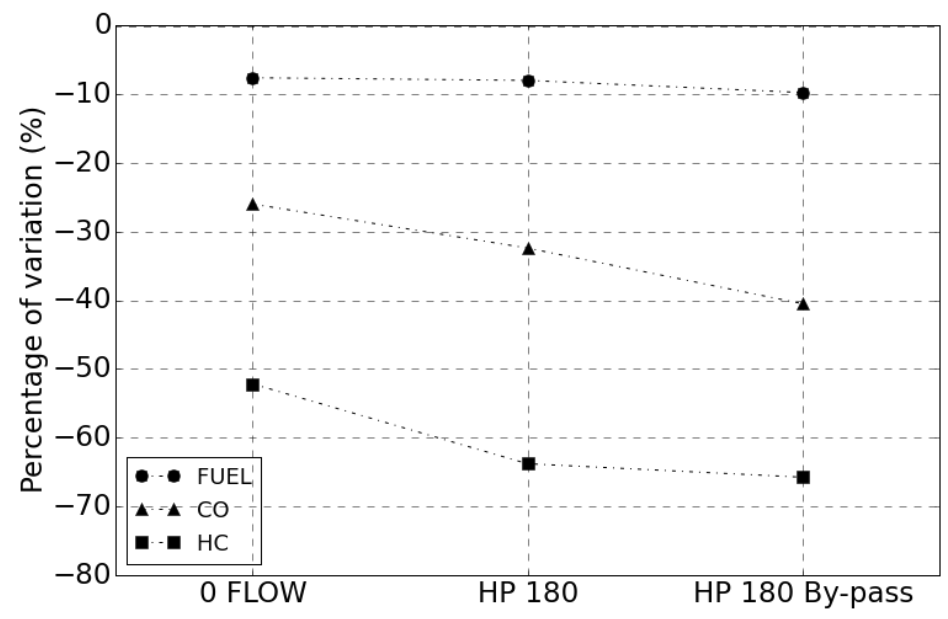

Figure 9. Total variation of fuel and pollutant emissions at $-7 \stackrel{\circ}{ } \mathrm{C}$.

\subsection{Influence of the ambient temperature}

In the following section, the effect of different ambient temperatures is analyzed. In this study, the HP 180 configuration is compared to the 0 -flow case. The reason to choose 0 -flow as reference, instead of AIRCAC case, is to evaluate the impact of the exhaust recovery system compared to a thermal management improvement (e.g. 0 -flow). Due to the fact that the heat recovery system is based on the existence of a WCAC which is connected to the TFE, the comparison between a WCAC 0 -flow configuration versus the TFE configuration is useful in order to determine the benefits of adding a TFE.

Results obtained in pollutant emissions for all ambient temperatures are compared in Figure 10. In all cases fuel reduction is negligible. $\mathrm{CO}$ emissions improvements are remarkable with a reduction of $9 \%$ at -7 and $7 \%$ at $0 \stackrel{\circ}{\circ}$. Greater reductions are obtained for unburned hydrocarbons with a reduction of $24 \%$ and $17 \%$ at -7 and $0{ }^{\circ} \mathrm{C}$ respectively. As ambient temperature increases, the benefits of the heat recovery system become lower. Once ambient temperature reaches $10^{\circ} \mathrm{C}$, the heat recovery system does not present significant differences.

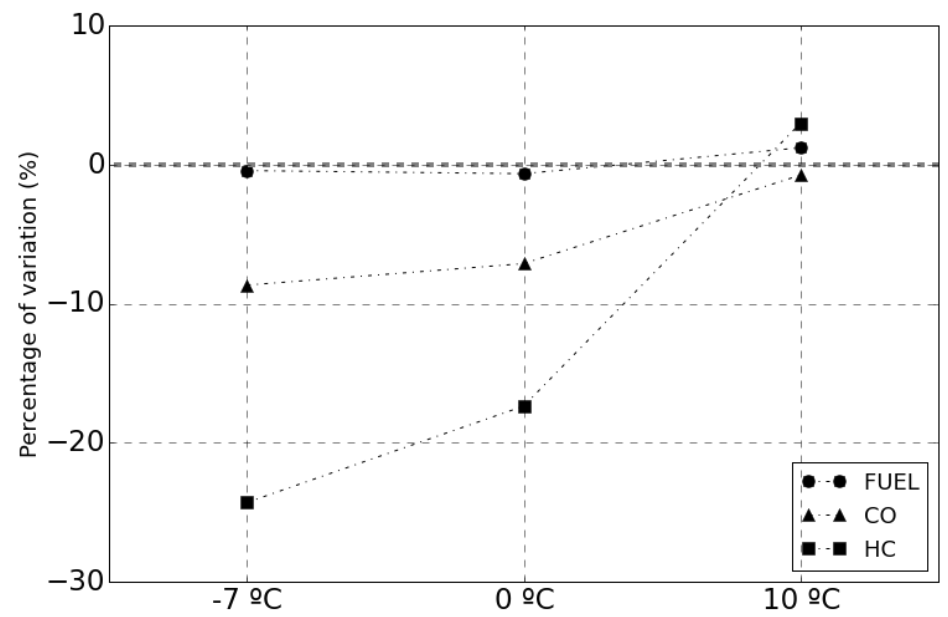

Figure 10. Total variation of fuel and pollutant emissions at different ambient temperatures. 


\section{Conclusions}

In this paper an experimental study was carried out in order to evaluate the potential of intake air heating, based in a novel exhaust heat recovery system, applied under low ambient temperatures during a NEDC cycle. Regarding intake air, its temperature greatly influences on engine pollutant emissions, pointing the importance of chemical reactiveness, driven by gas temperature, at the beginning of combustion.

TFE combined with HP EGR 180 and HP EGR 180 By-pass seconds duration becomes a solution to engine operation at low ambient temperature. HC and CO emissions in HP EGR 180 case have been significantly reduced with a maximum reduction around $65 \%$ and $32 \% \%$ respectively. Fuel consumption reduction is about $7 \%$. HP EGR 180 By-pass shows a bit higher improvements at CO with $40 \%$ of reduction and fuel consumption with $10 \%$ of reduction.

Compared to other thermal management systems like 0 -flow, the effect of the TFE is noticeable at low temperatures, with a reduction around $10 \%$ and $25 \%$ on carbon monoxide and unburned hydrocarbons respectively. As the ambient temperature increases, advantages of intake air heating become lower since pollutant emissions are less reduced. The fuel consumption is not affected by the ambient temperature in case of comparing TFE cases to 0 -flow.

\section{Aknowledgments}

This research has been partially financed by the Ministerio de Economía y Competitividad of Spain, through project IPT-370000-2010-022 'Investigación y desarrollo de tecnologías de EGR adaptadas a las nuevas arquitecturas y requerimientos de refrigeración en motores diésel sobrealimentados para automoción (HIREFIRE)'. The authors gratefully appreciate this support. Authors want to acknowledge the "Apoyo para la investigación y Desarrollo (PAID)" grant for doctoral studies (FPI S2 2015 1062). 


\section{References}

1. Bin Guan, Reggie Zhan, He Lin , Zhen Huang. Review of the state-of-the-art of exhaust particulate filter technology in internal combustion engines. Journal of Environmental Management 154 (2015) 225-258.

2. Federico Millo, Maurizio Andreata, Mahsa Rafigh, Davide Mercuri, Chiara Pozzi. Impact on vehicle fuel economy of the soot loading on diesel particulate filters made of different substrate materials. Energy 86 (2015) 19-30.

3. Ulrich G. Alkemade, Bernd Schumann. Engines and exhaust after treatment systems for future automotive applications. Solid State lonics 177 (2006) 2291-2296.

4. José M Desantes, José M Lujan, Benjamín Pla and José A Soler. On the combination of high pressure and low-pressure exhaust gas recirculation loops for improved fuel economy and reduced emissions in highspeed direct-injection engines. International Journal of Engine Research February 2013 14: 3-11.

5. A.J. Torregrosa , P. Olmeda, J. Martnal of Degraeuwe. Experiments on the influence of inlet charge and coolant temperature on performance and emissions of a DI Diesel engine. Experimental Thermal and Fluid Science 30 (2006) 633-641.

6. A. J. Torregrosa, A. Broatch, P. Olmeda and C. Romero. Assessment of the influence of different cooling system configurations on engine warm-up, emissions and fuel consumption. International Journal of Automotive Technology, Vol. 9, No. 4, pp. 447-458 (2008). DOI 10.1007/s12239-008-0054-1.

7. P. J. Shayler and S. J. Christian. A Model for the Investigation of Temperature, Heat Flow and Friction Characteristics During Engine Warm-Up. SAE technical paper 1993 : 931153.

8. Romero, C., Torregrosa, A., Olmeda, P., and Martin, J. Energy Balance During the Warm-Up of a Diesel Engine. SAE Technical Paper 2014-01-0676, 2014.

9. M. Gumus. Reducing cold-start emission from internal combustion engines by means of thermal energy storage system. Applied Thermal Engineering 29 (2009) 652-660

10. Alberto Broatch, José M. Luján, José R. Serrano and Benjamín Pla. A procedure to reduce pollutant gases from Diesel combustion during European MVEG-A cycle by using electrical intake air-heaters. Fuel 87 (2008) 2760-2778.

11. Pertti Kauranen, Tuomo Elonen, Lisa Wikström, Jorma Heikkinen and Juhani Laurikko. Temperature optimisation of a diesel engine using exhaust gas heat recovery and thermal energy storage (diesel engine with thermal energy storage). Applied Thermal Engineering 30 (2010) 631-638.

12. Diehl, P., Haubner, F., Klopstein, S., and Koch, F. Exhaust Heat Recovery System for Modern Cars, SAE Technical Paper 2001-01-1020, 2001, doi:10.4271/2001-01-1020.

13. Ap, N. and Golm, N. Insulated Expansion Tank (IET) and Thermal Storage for Engine Cold Start. SAE Technical Paper 950994, 1995, doi:10.4271/950994..

14. Arrhenius, S.A. "Über die Dissociationswärme und den Einflusß der Temperatur auf den Dissociationsgrad der Elektrolyte". Z. Physik. Chem. 4: 96-116.

15. G. De Nicolao, R. Scattolini and C. Siviero. Modelling the volumetric efficiency of IC engines: parametric, non-parametric and neural techniques. Control Eng. Practice, Vol. 4, No. 10, pp. 1405-1415, 1996.

16. José Manuel Luján, Héctor Climent, Benjamín Pla, Manuel Eduardo Rivas-Perea, Nicolas-Yoan François, Jose Borges-Alejo, Zoulikha Soukeur. Exhaust gas recirculation dispersion analysis using in-cylinder 
pressure measurements in automotive diesel engines. Applied Thermal Engineering, 2015, Volume 89, pp. 459-468

17. Payri F, Lujan J, Climent $\mathrm{H}$, Pla B. Effects of the Intake Charge Distribution in HSDI Engines. SAE Technical Paper, (2010) 2010-01-1119, doi: 10.4271/2010-01-1119.

18. David C. Quiros, Seungju Yoon, Harry A. Dwyer, John F. Collins, Yifang Zhu, Tao Huai. Measuring particulate matter emissions during parked active diesel particulate filter regeneration of heavy-duty diesel trucks. Journal of Aerosol Science 73 (2014) 48-62.

19. J. Arregle, V. Bermúdez, J.R. Serrano, E. Fuentes. Procedure for engine transient cycle emissions testing in real time. Experimental Thermal and Fluid Science 30 (2006) 485-496

20. J. Todd Messer, Nigel N. Clark, and Donald W. Lyons. Measurement Delays and Modal Analysis for a Heavy Duty Transportable Emissions Testing Laboratory. SAE Technical Paper 950218, 1995, doi:10.4271/950218.

21. Konstantas G, Stamatelos A. Quality assurance of exhaust emissions test data. Proceedings of the Institution of Mechanical Engineers, Part D: Journal of Automobile Engineering August 1, 2004 218: 901 914.

22. P. Bielaczyc J. Merskisz. Cold start emissions investigation at different ambient temperature conditions. SAE paper 980401, 1998.

23. F. Payri, P. Olmeda, J. Martín, R. Carreño. Experimental analysis of the global energy balance in a DI Diesel engine, Applied Thermal Engineering (2015), doi: 10.1016/ j.applthermaleng.2015.06.005

24. Imdat Taymaz. An experimental study of energy balance in low heat rejection diesel engine. Energy 31 (2006) 364-371.

25. Ramesh K. Shah, Dusan P. Sekulic . Fundamentals of Heat Exchanger Design. John Wiley \& Sons. Page 140. 